HAESBAERT, Rogério; PEREIRA, Sergio Nunes; RIBEIRO, Guilherme (Orgs.). Vidal, Vidais: textos de Geografia Humana, Regional e Política. Rio de Janeiro: Bertrand Brasil, 2012. 464p.

\title{
(Re)Conhecendo a Geografia Humana de Paul Vidal de la Blache
}

\section{(Re)Cognizing the Human Geography of Paul Vidal de la Blache}

\author{
Carlos Alberto Menarin ${ }^{1}$
}

\begin{abstract}
No início do século 20, o casal história/geografia abandona os princípios da Pátria para se desvencilhar do Estado e se afastar da política. Ele foge, vai descansar e encontra, feliz, uma França do interior acolhedora, resplandecente em sua diversidade regional.
\end{abstract}

(François Dosse)

Seria colocar uma venda nos olhos estudar uma região isoladamente, como se ela não fizesse parte de um conjunto.

(Paul Vidal de la Bache, 1894)

Com aquelas primeiras palavras o historiador francês François Dosse inicia um artigo dedicado a um breve percurso da relação entre História e Geografia no âmbito da formação do campo historiográfico na França. Publicado originalmente na revista Espaces Temps, em 1998, foi traduzido para o português em 2004 e compõe a coletânea História e Ciências Sociais ${ }^{2}$. Na perspectiva do artigo, do qual extraímos a epígrafe, o

\footnotetext{
${ }^{1}$ Doutor em História pela UNESP/Assis. Colaborador do Laboratório de História e Meio Ambiente (LABHIMA) do Departamento de História da UNESP/Assis. Bolsista Pósdoutorado do Programa Nacional Pós-Doutoramento da CAPES. E-mail: camenarin@yahoo.com.br

${ }^{2}$ Cf. DOSSE, François. O recurso geográfico dos historiadores. In: História e Ciências Sociais. Tradução Fernando Abreu. Bauru: Ed. USC, 2004. p. 115-148. 
movimento de renovação historiográfico empreendido por Marc Bloch e Lucien Febvre a partir da fundação da revista Annales d'Histoire Économique et Social se deu decisivamente no diálogo com a Geografia Humana francesa cuja formulação se dá sob o pensamento de Paul Vidal de la Blache. Duramente criticado pela sociologia durkheimiana, é Febvre que sai em defesa da perspectiva geográfica com a publicação, em 1949, de $L a$ terre et l'évolution humaine. Introduction géographique à l'histoire. Marcase aí um ponto crucial de aproximação e, ao mesmo tempo, de distanciamento dessas disciplinas, que sob a perspectiva da História, passa a tratar a Geografia como disciplina "auxiliar". Emerge uma perspectiva que trata a contribuição da geografia lablachiana acerca do recorte regional, que teria orientado o esquadrinhamento das pesquisas histórias sobre o território francês.

Esse movimento é bastante conhecido no debate historiográfico sobre a configuração da "escola histórica" francesa. No tocante ao Brasil, cabe lembrar o papel central que essa historiografia teve (e continua tendo) na institucionalização da pesquisa universitária em História, inicialmente, com a configuração do curso de História e Geografia na Universidade de São Paulo (criada em 1934), a cargo da chamada "missão francesa", de futuros expoentes no campo da Geografia, Sociologia e História, como Pierre Monbeig, Roger Bastide e Fernand Braudel, respectivamente, dentre outros professores.

Como é salutar em todo processo de construção do conhecimento, periodicamente essas formulações podem ser (re)equacionadas sob novos olhares e questões. É com essa relevância que a obra organizada pelos geógrafos Rogério Haesbaert, Sergio Nunes Pereira e Guilherme Ribeiro traz aos leitores brasileiros um Vidal de la Blache praticamente desconhecido, múltiplo - que não cabe na leitura quase sempre de segunda mão e enviesada pela perspectiva dada por Lucien Febvre, que o circunscreve a análise dos quadros regionais e de uma geografia possibilista em contraposição ao atribuído determinismo do alemão Friedrich Ratzel.

São 24 textos de Paul Vidal de la Blache, organizados em três eixos: uma primeira parte procurando dar conta da Geografia Humana desse autor, atinando para o percurso intelectual e sua contribuição epistemológica para essa perspectiva geográfica; a seguinte apresentando sua significativa reflexão sobre os "recortes regionais", cuja conectividade buscada pela noção de unidade terrestre procura responder a questões colocadas pelo processo de transição de um mundo rural e agrário para o urbano-industrial; e por fim, uma terceira parte apresentando os aspectos políticos de sua obra, 
dialogando com a problemática dos Estados, das nações e, em particular, das ações do colonialismo francês. O livro conta ainda com três importantes textos críticos e introdutórios a cada uma das partes assinados pelos organizadores do volume (Guilherme Riberio, Rogério Haesbaert e Sergio Nunes Pereira, respectivamente), além do prefácio de Paul Claval.

Partindo do quase lugar-comum de seu apreço à abordagem regional, pouco se conhecia de seu interesse pela dinâmica econômica e seu impacto na organização do espaço. Os recortes regionais de Vidal são centrais na medida em que respondem ao seu projeto de descrição da diversidade terrestre, com diálogo entabulado com geólogos e cientistas naturais, além da história (curiosamente sua disciplina de formação), perscrutando assim desde o subsolo, o relevo e o clima às variedades e dinâmica das paisagens. Essa perspectiva evidencia uma característica da metodologia de Vidal que se deve destacar: a visão de conjunto, tal como expresso no prefácio do Altlas Général, publicado em 1894, cujo excerto da segunda epígrafe indica.

Ou seja, um de seus fundamentos é o de articular boa parte de seus trabalhos à concepção de unidade da Terra. Não se trata de um todo homogêneo, daí a relevância das partes e de suas conexões para compreensão do todo. Uma visão de conjunto tributária das Ciências Naturais do século XIX. Os lugares e as paisagens revelariam uma exuberante diversidade. Amarrar as partes ao todo pressupõe um exercício de observação de escalas múltiplas e das realidades complexas comparáveis - outra característica de seu método, a comparação. Mas para a rigorosa compreensão dessas distintas realidades, apenas os recursos geológicos ou das Ciências Naturais não são suficientes, abrindo o necessário diálogo e com os conhecimentos das Ciências do Homem - ou seja, o que chamamos hoje de interdisciplinaridade como instrumento metodológico incontornável na geografia de Vidal de la Blache.

Somando esses às observações de campo, com destaque para a leitura da paisagem como um documento indicativo das transformações do meio natural e das formas de organização social, temos um método complexo e aberto à apreensão das diferentes formas de manifestação social sobre o espaço a as transformações mútuas decorrentes dessa relação, como sob os conceitos de paisagem e gêneros de vida.

$\mathrm{O}$ que se poderia chamar de uma epistemologia vidaliana, constitui um arcabouço teórico-metodológico de importância para o historiador, em particular o interessado na dinâmica relação entre as sociedades e o meio ambiente. Partindo do território (em sua acepção mais física) rumo às 
formas de estabelecimento humano, retorna assim ao território lá modificado. Temos assim um movimento que busca a relação homem-meio e seus desdobramentos pela transformação humana da natureza através da técnica e da cultura; e o quadro político, incidindo nas disputas espaciais promovidas notadamente por Estados Nacionais e Impérios que refletem e agem sobre essa dinâmica sócio-espacial.

O próprio encadeamento dos textos selecionados para cada parte temática, de maneira cronológica ascendente, reflete parte da dinâmica do pensamento de Vidal de la Blache - sendo um dos exemplos a sucessiva reflexão e o grau de complexidade sobre o qual vai sendo construído e reconstruído o conceito de região expressado na segunda parte do livro.

Articulado particularmente as duas últimas parte, podemos destacar a desmistificação da suposta contenda com o geógrafo alemão Friedrich Ratzel - ilustrado pelo quase lugar-comum possibilismo versus determinismo, envolvendo, respectivamente, supostas correntes geográficas que dariam identidade as obras dos dois geógrafos. Muito mais que opositor de Ratzel, Vidal teria dialogado com as reflexões do geógrafo alemão, contribuindo para formulação de suas próprias questões - como a tarefa estratégica de controle do território pelo Estado, cujo quadro de fundo a política colonialista encontra-se latente. Ou seja, entre o suposto embate possibilismo-determinismo, a dimensão política do contexto colonial do período, em particular o Francês, não pode ser minimizada acerca do pensamento geográfico da época. Segundo Sérgio Nunes Pereira, "Vidal realizou uma leitura da situação europeia e da influência francesa no mundo que constituiu um importante registro de sua época, num contexto de redefinição do papel das principais potências no cenário global”. (p. 338339) Ou seja, "do primeiro trabalho de fôlego ao último livro escrito em vida - convidam a repensar a imagem do autor como um acadêmico alheio aos temas de geografia política". (p. 359)

A publicação da presente coletânea é, sem dúvida, muito bem vinda para além da comunidade dos geógrafos. Gerações de historiadores franceses, em particular àqueles estabelecidos em torno da revista annales, dialogaram com o pensamento de Vidal de La Blache, do qual nos chegaram apenas ecos e leituras indiretas. A hipótese defendida pelos autores é a de que a Geografia vidaliana, com todas suas idas e vindas, "representou uma perspectiva científica de vanguarda no ambiente intelectual francês na virada do século XIX para o XX, proporcionando, ainda hoje, releituras e debates importantes". (p. 15) 
No Brasil, o diálogo dos historiadores com a produção dos geógrafos já foi intensa e relevante para a historiografia. Atualmente figura um afastamento descabido. O (re)conhecimento da Geografia Humana de Paul Vidal de la Blache que o presente volume oferece é uma vereda aberta para a compreensão da dimensão desse diálogo, por exemplo, sobre a geração de historiadores e geógrafos formados pelos professores franceses, dentre outros, Pierre Monbeig e Fernand Braudel, que dialogaram abertamente com a obra e o pensamento vidaliano.

Os historiadores contemporâneos interessados nas relações sociedade e natureza ao longo do tempo, em particular identificados sob a chamada História Ambiental - onde a dimensão biofísica ganha relevância têm na possibilidade de diálogo com pensamento geográfico uma importante ferramenta para instrumentalizar as pesquisas sobre uma dimensão espacial, a muito destreinado em considerar; além de outras perspectivas que a presente obra oferece de releituras e de possibilidades de novos entendimentos sobre a produção geográfica e historiográfica do Brasil. 